\title{
APPLYING LINGUISTICS TO SPEECH AND LANGUAGE THERAPY FOR APHASICS*
}

\author{
H. Joan Morley \\ University of Michigan
}

In the field of speech correction one of the most interesting and challenging problems is that of speech and language therapy for adult aphasics. Aphasia may be described as the impairment of speech and language functions of expression and/or comprehension. The individual may have partial or complete loss of the ability to use speech and language symbols and/or to understand speech and language symbols. Aphasia is the result of brain damage due to injury, disease, or maldevelopment of the brain.

Although direct help in regaining the use of speech and language is the primary concern of the speech therapist, other corollary problems must also be taken into consideration in total rehabilitation of the patient. These include physical, psychological, and emotional problems which have resulted from the original brain damage and the patient's reactions to his disabilities. If the reader is interested in a more detailed discussion of the many-faceted problems of the aphasic, he may refer to the writings of Joseph Wepman, ${ }^{1}$ Longerich and Bordeaux, ${ }^{2}$ and others in this field. This paper will be concerned only with the speech and language aspects.

It is the purpose of this paper to outline suggestions for language therapy designed to present a practical approach to language retraining for aphasic individuals. It attempts to strengthen the weaknesses of other methods which have left the aphasic person with the ability to use isolated words but the inability to

*The writer wishes to express appreciation to Dr. H. H. Bloomer, Director, Speech Clinic, University of Michigan, Miss Maryanna Bender, Senior Clinician in the Dysphasia Division, and Dr. Ralph P. Barrett of the English Language Institute, for their assistance.

${ }^{1}$ Joseph Wepman, Recovery from Aphasia, The Ronald Press, New York, 1951.

2M. C. Longerich and J. Bordeau, Aphasia Therapeutics, The MacMillan Company, 1954. 
put these words into usable connected patterns of language. In examining the possibilities for improved therapy recent thinking in the general field of language was investigated. Ideas from the field of structural linguistics, specializing in the analysis, revision, and presentation of better methods of teaching language, were found to be the most usable.

In examining literature in the field of structural linguistics two ideas were particularly applicable in planning more profitable language therapy for aphasics. The first concerns the very basic concept of the process involved in original language learning of children. The patterns of language are learned by hearing and trying to repeat them over and over again. It is particularly important to stress the term "patterns of language" not just words or structure. The second idea concerns Charles Fries ${ }^{3}$ presentation of signals of structure as formal matters which can be described in physical terms in the study of language.

Applying these ideas from the field of linguistics the therapy suggestions to be outlined are based on three items. The first two are basic factors which were operative in the original process of language learning: (1) stimulation with total patterns of expression, and (2) the patient's own trial and error attempts to use total patterns of expression. The third involves the use of concrete cues or signals identifying the function of different kinds of words in patterns as scientifically and precisely presented by structural linguistics.

The therapy suggested does not rely on memorization of words or drill in word calling alone. The weakness of such drill lies in leaving the aphasic with the use of parts and pieces of language but the continued inability to use them in meaningful patterns. Neither does it employ the presentation of the traditional "rules of grammar" which has proved unsuccessful in bridging the gap between isolated words and their meaningful use. M. H. Scargill in suggesting that the language therapist might be able to borrow valuable material from structural linguistics summarized the latter problem as follows:

The traditional grammars, with their insistence upon "meaning" as the sole means of language learning, can be of little aid to a therapist who has great difficulty in communicating "meaning." 4

${ }^{3}$ Charles Fries, The Structure of English, Harcourt Brace, and Company, New York, 1952.

${ }^{4}$ M. H. Scargill, "Modern Linguistics and Recovery from Aphasia," The Journal of Speech and Hearing Disorders, December, 1954, p. 507. 
All therapy materials presented in the following outline have been prepared dealing with words as they function within a given sentence or pattern. No word is presented as a single unit and left as such. Words have been presented within the context of written sentences, written questions, spoken sentences and spoken questions. A word may be presented on a word card and discussed as an individual unit but it is always put back into a complete pattern within the framework of the same lesson. Different classes of words have been stressed, one at a time, together with their identifying markers and patternings. The use of the different kinds of words has been stressed not through formal explanation but through consistent and repetitive presentation of controlled examples (moving from simple to complex over a prolonged period of therapy).

This therapy approach is based on the assumption that prolonged and controlled stimulation with these patterns (originally on a very simple and a very controlled basis) and the insistence on the patient's own trial and error attempts to use these same patterns in the therapy lessons will eventually result in their carry-over into informal language situations. Thus the aphasic individual will have the grasp of a number of complete patterns of expression (though perhaps limited) upon which he can rely and into which he can fit his desired verbal communications.

\section{Preparation of Materials for Therapy}

\section{Content of Materials}

A. Stories

The stories should be written by the therapist, mimeographed, given to the patients, and/or written on the blackboard.

\section{Interest Level}

The stories should contain subject matter geared as nearly as possible to the interests of the group.

2. Vocabulary Level

The stories should be constructed using vocabulary geared as nearly as possible to the comprehension level of the group. The level of the vocabulary can be increased gradually as the program progresses. The vocabulary should be practical to the patient in his immediate environment. 


\section{Markers of Word Functions}

The stories should be constructed illustrating (1) the features of form, (2) accompanying function words, and (3) patterning in a sentence of the different word classes as outlined by Fries. Emphasis should be placed on one class at a time.

\section{B. Exercises and Questions}

The exercises and questions should be prepared by the therapist, mimeographed, and given to the patients, and/or written on the blackboard. They should be designed to increase and check comprehension of the reading materials in one or all of the three areas presented below.

1. Total Comprehension of the Reading Material

2. Understanding New Vocabulary Words

3. Understanding of the Functional Uses of Words

The stress will be placed on understanding of the markers of word functions described above.

II. Structure of Materials

A. Structure of the Stories

1. Vocabulary

The words to be stressed for broadening vocabulary and increasing comprehension of written material should be systematically selected and presented.

a. Word Functions

Particular language problems of the aphasic lie in the use of correct verb tenses, correct noun numbers, use of pronouns, connectives and other "linking" words, and in difficulty with sentence order. Since outright explanations of these items are difficult for the aphasic to understand, the teaching materials have been structured to stress one group of words at a time following the form classes and function word groups as outlined by Fries. ${ }^{6}$ The stories have been constructed to present the markers of the form class words (those words which

${ }^{5}$ Charles Fries, op. cit.

${ }^{6}$ Charles Fries, op. cit. 
carry content or meaning) and the patternings of the function word groups (those words which link and help determine precise interpretation of the form class words.)

It is important to note that although words may be classed into these two big groups and their various subgroups, words are not entirely stable and can slip from one class to another. This makes it important to deal with words only as they function within a given sentence. Although no technical explanations of words and their functions will be presented to be learned as such, some discussion of this matter will be undertaken as the lessons demand.

b. Form Classes

The English language employs the use of four form classes: Class 1 (generally nouns and pronouns), Class 2 (generally verbs), Class 3 (generally adjectives) and Class 4 (generally adverbs). Each class has a general meaning: Class 1 (naming), Class 2 (action), Classes 3 and 4 (quality). When used in sentences a number of identifying markers clearly indicate that words are members of particular classes. Fries ${ }^{7}$ defines three such ways in which words may be marked: (1) by something in the word itself (features of form such as suffixes and prefixes), (2) by function words that accompany it, and (3) by the position and pattern in a sentence.

Some of the markers of the form classes are very rigid while others are more flexible. At the beginning of therapy the therapist, by preparing materials which adhere closely to the more rigid markers of form class, can help the patient begin to grasp the function of each of these kinds of words in a sentence pattern.

c. Function Word Groups

Function word groups differ from form classes in several ways: (1) each contains few words whereas each form class contains thousands, (2) they are not

\footnotetext{
${ }^{7}$ Charles Fries, op. cit.
} 
marked by features of form, (3) they serve only to expand the basic patterns, and (4) some function word groups pattern consistently with certain form classes.

The functional word groups can be taught as they pattern with words of the form classes to help the patient begin to grasp the function of each of these kinds of words in sentence patterns. Since space does not permit a complete discussion of all word groups the reader is referred to Roberts ${ }^{8}$ and Fries.

\section{Sentence Structure}

In composing sentences for the stories careful attention should be given to the use of one or more of the identifying markers of the form classes each time such words are used. Words from the functional words groups may be used in their appropriate patterns with words from the form classes.

By adhering closely to the identifying markers previously discussed the therapist can prepare materials which give consistent stimulation with the functional patterns of the different kinds of words. Rather than being given rules for structure the patient is given continuous stimulation with the complete patterns of structure. For example, the functions of nouns (Class 1 ), verbs (Class 2 ), adjectives (Class 3 ), and adverbs (Class 4 ) can be taught by illustrations of their use in sentences rather than by memorization of rules for their use. It is felt that this stimulation together with some knowledge of the identifying markers will give the patient a practical foundation for the understanding and use of basic English language structure.

Stories should be constructed using the seven basic sentence patterns. ${ }^{y}$ These patterns can be expanded into longer constructions by the use of modifying groups but the same basic patterns remain. Other more complex sentence structures can be omitted initially.

York, 1956 ,

${ }^{9}$ Paul Roberts, op. cit., p. 298. 


\section{Paragraph Structure}

Length of the paragraph can be four or five sentences. The number of paragraphs can be increased from one to four or more paragraphs as the program progresses.

\section{B. Structure of the Exercises and Questions}

The exercises and questions should be designed to increase and check comprehension of the reading materials. They should be geared to one or all of three areas: (1) total comprehension of the material, (2) understanding of vocabulary words, and (3) understanding of the functional uses of words.

The exercises and questions should be structured following the same plan outlined for construction of the reading materials. These materials should use the same identifying markers and patterns used in the stories.

When the materials require the patient to supply a word, as many identifying markers as possible should be used to confine the choice of an answer to one specific type of word. Specific markers of the form classes may be used to this end with the function words used as they pattern with them. In this way the question materials not only check and help to increase comprehension but can facilitate the learning of word functions.

\section{Presentation of Therapy Materials}

\section{Stories}

The printed stories prepared as outlined in the previous section are given to each patient. The patients read the material silently.

Example:

\section{SPRING}

April is here. Spring is in the air. Spring is a beautiful season of the year. We see many signs of spring.

Warm weather is a sign of spring. The sunshine is bright. The sky is blue. The air is warm.

Many sports are a sign of spring. Baseball is one spring sport. Spring is the best season for baseball. We can sit in the warm sunshine and watch the baseball games. 
II. Exercises and Questions ${ }^{10}$

A. Purpose

Various kinds of exercises and questions designed to increase and check comprehension are given to the patients. The exercises may be given orally, on printed sheets, or written on the blackboard. The exercises have beengeared to one or all of three areas: (1) total comprehension of the material, (2) understanding of vocabulary words, and (3) understanding of the functional uses of words.

B. Presentation

The patients may write the answers or give them orally. They are sometimes permitted to use the story sheet for reference in answering the questions and are sometimes not permitted to do so. Examples of eighteen different kinds of exercises will be discussed.

1. Completion exercises (with blanks to be filled in with one word answers)

a. Stress on comprehension of the reading material Examples:

(1) The is blue. (sky)

(2) Many sports are a of spring. (sign) (Note: determiners $\bar{a}$ and the preceding the blank area signal that a Class 1 word is needed)

(3) We can in the warm sunshine. (sit)

(4) We will to the mountains. (drive) (Note: auxilliaries can and will preceding the blank area signal that a Class 2 word is needed)

b. Stress on understanding new vocabulary words Examples:

(1) The in Brazil is hot. (climate)

(2) The is rich and red. (soil)

(Note: determiners $a$ and the preceding the blank signal that a Class 1 word is needed)

(3) Coffee is in Brazil. (grown)

(4) Tall trees are for shade. (planted)

(Note: auxilliaries is and are preceding the blank signal that a Class 2 word is needed)

(5) Brazil is famous for the coffee. (finest)

$1^{10}$ Some exercises and questions given as examples refer to the sample story, Spring; others are drawn from other stories presented during the course of experimentation with this method of therapy. 
(6) Brazil is a very country. (beautiful)

(Note: the determiner preceding the blank and the Class 1 word following it signal that a Class 3 word is needed; the-est form of a word and the use of the intensifier very are additional signals that a Class 3 word is needed)

(7) Coffee trees grow -ly in good soil. (rapidly)

(8) He walked down the road very -ly. (slowly) (Note: the use of the intensifier very and the $-l y$ word form signal that a Class 4 word is used)

c. Stress on understanding of the functional uses of words

(Note: the functional word groups of determiners, auxilliaries, and intensifiers are taught along with the form classes with which they pattern as discussed above)

2. Questions using question words (to be filled in primarily with one or two word answers)

a. Stress on comprehension of the reading material Examples:

(1) How much did the bridge cost? (ten million dollars)

(2) What color are the leaves on coffee trees?

(dark green)

b. Stress on understanding new vocabulary words (with the words stressed appearing in either the question or the answer)

Examples:

(1) What season is now beginning? (spring)

(2) What state is Flint in? (Michigan)

c. Stress on understanding of the functional uses of words

Examples:

(1) Where was thercontest held? (in Ann Arbor)

(Note: the question word where implies an answer of place)

(2) When did the game take place? (on Friday) (Note: the question word when implies an answer of time) 
(3) Why does coffee grow best in Brazil? (good climate and good soil)

(Note: the question word why implies an answer of reason or explanation)

3. Matching questions

a. Stress on comprehension of the material Examples:

(1) Who brought the pie? (1) Mrs. Jones

(2) Who brought the cake? (2) Mrs. Smith

b. Stress on understanding new vocabulary words Examples:

(1) What is the length of the field? (1) 10 feet

(2) What is the height of the tower? (2) 90 feet

c. Stress on understanding of the functional uses of words

(Note: the same emphasis can be placed on the implications of each question word as already discussed)

4. Short-answer questions

a. Stress on comprehension of the material, understanding new vocabulary words, and understanding of the functional uses of words

Examples:

(1) What four states are famous for special foods? (Florida, Idaho, Maine, California)

(2) What are the months of the coffee harvest? (March, April, May, June, July, and August)

5. Discussion or explanation exercises

a. Stress on high level comprehension of the material, understanding of the functional uses of words

Examples:

(1) Tell three things about the new 1959 cars. (They will be longer, wider, and shorter.)

(2) Give two reasons for having our picnic early. (More people will be able to come and it will be before the rainy season.) 
6. Questions to classify or categorize materials

a. Stress on comprehension of the material, high level understanding of new vocabulary words, and under standing of the functional uses of words

Examples:

(1) Which cars are made by each of the following companies: General Motors, Ford, and Chrysler? (lists to be made of those discussed in the story)

(2) What states and towns were discussed in the story? (lists to be made of those discussed in the story)

7. Multiple choice completion questions (correct answer is only word of its class given as a choice)

a. Stress on understanding of the functional uses of words

Examples:

(1) The

(1) slowly is planned for Monday.

Mrs. Brown is baking a

(1) cake

(2) beautiful (3) ran

(Note: Determiners $a$ and the preceding the blank signal that a Class 1 word is needed.)

(3) Many guests have been
(1) invited
(2) cake

(4) The picnic may be

(1) postponed (2) red

(3) rainy if it rains.

(Note: auxilliaries have been and may 1 be preceding the blank signal that a Class 2 word is needed.)

8. Muitiple choice completion questions (all choices are words of the same class)

a. Stress on comprehension of the material

Examples:

(1) Mrs. Smith is fixing the
(1) salad
(2) hot dogs

is planned for Monday.

(2) The
(2) picnic
(3) dance
(1) party 
9. Multiple-choice substitution questions (a synonym is to be substituted for the vocabulary word with all choices in the same word class.)

a. Stress on understanding new vocabulary words Examples:

(1) The driver suddenly realized the danger.
(1) became aware of
(3) increased
(2) became alarmed at
(4) forgot

(2) A strange story was related by the boy.
(1) admitted
(2) remembered
(3) doubted
(4) told

10. Multiple-choice substitution questions (a vocabulary word is to be substituted for the synonym with all choices in the same word class.)

a. Stress on understanding new vocabulary words

Examples:

(1) The fliers were told to go to the height of 30,000 feet.
(1) altitude
(3) length
(2) size
(4) breadth

(2) The cold weather made the trip impossible.
(1) scenery
(2) story
(3) journey
(4) country

11. Completion matching questions (correct word to be matched to correct sentence and the blank filled in)

a. Stress on comprehension of the material

Examples:

dark green

cherries

two

one-half inch

small

(1) Coffee berries are long.

(2) The leaves on coffee trees are in color.

(3) The coffee berries look like red

(4) coffee beans are inside each berry.

(5) $\overline{\text { Many }}$ have flowers blooming.

(Note: various identifying markers preceding the 
blanks indicate the class of the word to be supplied.)

b. Stress on understanding functional use of words Examples:

to

from

in

with

(1) Mr. Jones came Detroit to Ann Arbor.

(2) The chalk is the box.

(3) I went to the show Jim.

(4) I will go Detroit next weekend.

12. Substitution matching questions (a vocabulary word is to be substituted for the synonym used in the sentence.)

a. Stress on understanding new vocabulary words

Examples:

enjoy

beginning

building

season

(1) This is the time of year for baseball.

(2) Many people like the ball games.

(3) Birds are making nests.

(4) Leaves are starting to come out.

(Note: various identifying markers preceding the underlined words indicate the class of the word to be supplied.)

13. Substitution matching questions (a synonym is to be substituted for the vocabulary word used in the sentence.)

a. Stress on understanding new vocabulary words

Examples:

makes

well-liked

got

well-known

(1) General Motors manufactures cars.

(2) Bing Crosby is a famous man. 
(3) Baseball is a popular sport.

(4) Many people received cuts and bruises.

14. Extracting the main idea. of each paragraph of a story

a. Stress on comprehension of the material

Example:

(The patient is asked to write or tell the main idea.)

15. Composing titles for stories

a. Stress on comprehension of the material Example:

(The patient is asked to write or tell a good title for the story.)

16. Choosing a title for a story

a. Stress on comprehension of the material

Example:

(The patient is asked to choose the best title for the story from a choice of several possible titles.)

17. Composing a summary of the story

a. Stress on comprehension of the material

Example:

(The patient is asked to write or tell a summary of the important points of a story.)

18. Composing sentences using new vocabulary words

a. Stress on understanding new vocabulary words

Example:

(The patient is given a word and asked to write or tell a sentence using the word. If the sentences are given orally, they are written on the blackboard by the therapist and the structure is discussed by the group.)

It has been the purpose of this paper to present suggestions for therapy for use in the language rehabilitation of aphasics. The primary emphasis has been on the area of reading. The approach presented here differs from other therapy methods in that certain principles from the field of structural linguistics 
have been adapted and employed in its formulation. The materials and techniques described here have been used experimentally with reading groups of high level aphasics with reasonable success.11 It is hoped that further application of this approach to therapy will be made in order to evaluate more fully its strengths and weaknesses.

$11_{\text {The Dysphasia Division of the University of Michigan Speech }}$ Clinic has used a similar method of therapy stressing use of words in complete sentences successfully for a number of years. 